\title{
Removal of Cadmium(II) from Wastewater Using Novel Cadmium lon-Imprinted Polymers
}

\author{
$\mathrm{Yu} \mathrm{Xi}{ }^{\dagger}$ Yiting Luo, ${ }^{\dagger}$ Jinming Luo, ${ }^{\ddagger}$ and Xubiao Luo ${ }^{*}, \dagger$
}

${ }^{\dagger}$ Key Laboratory of Jiangxi Province for Persistent Pollutants Control and Resources Recycle, Nanchang Hangkong University, Nanchang 330063, P. R. China

${ }^{\ddagger}$ Key Laboratory of Aquatic Science and Technology, Research Center for Eco-Environmental Sciences, Chinese Academy of Sciences, Beijing 100085, P. R. China

\section{Supporting Information}

ABSTRACT: Cadmium ion-imprinted polymers (Cd-IIP) were synthesized by precipitation polymerization using a complex of dithizone and cadmium as a template. The saturation adsorption capacity of the Cd-IIP is two times that of the nonimprinted polymers (Cd-NIP). Homogeneous binding sites are confirmed by the Langmuir isotherm. The adsorption kinetics fit a pseudo-secondorder model well; and the adsorption equilibrium time is only approximately $20 \mathrm{~min}$. The effect of coexisting ions on the Cd(II)-IIP and NIP were investigated by competing with $\mathrm{Pb}(\mathrm{II}), \mathrm{Zn}$ (II), $\mathrm{Co}$ (II), and $\mathrm{Cu}(\mathrm{II})$, and the ratio of relative selectivity coefficients was greater than 1.68. Thermodynamic parameters indicated that $\mathrm{Cd}(\mathrm{II})$ adsorption over IIP and NIP was a spontaneous and exothermic process. The enthalpy changes in different temperatures and adsorption energy are lower than -20.0 and $8 \mathrm{~kJ} / \mathrm{mol}$; respectively. These indicate that the adsorption process may be dominated by physisorption. The Cd-IIP was used for five cycles with a small decrease in adsorption capacity, which validated a significant potential of Cd-IIP in wastewater treatment.
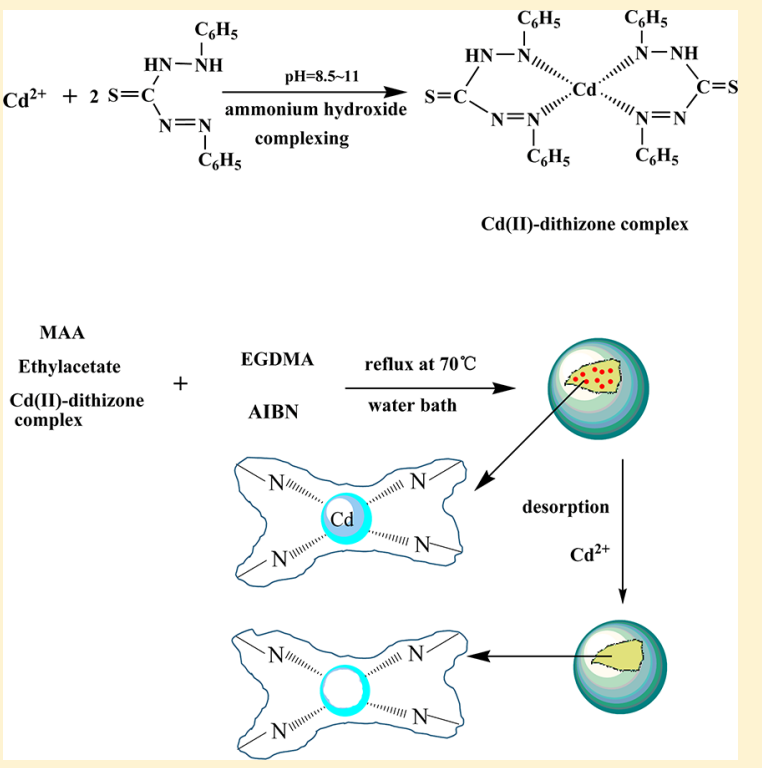

\section{INTRODUCTION}

The presence of cadmium in the natural environment is related to both natural (cadmium coexists in earth with zinc in copper mines) and anthropogenic discharge sources. The metal has various applications in electroplating, nickel-cadmium batteries, alloys, pigments, phosphors, pesticide, and many other

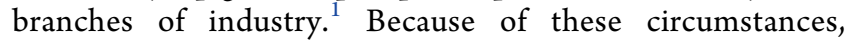
cadmium can be easily transferred into animals and human beings by smoke in the air, water, and food and subsequently accumulated in the body. ${ }^{2}$ Long-term exposure to cadmium has been demonstrated to have detrimental influence on the heart, lungs, bones, and especially, the kidneys. ${ }^{1}$ Because cadmium effortlessly passes through the food chain system of the earth and is transferred into human beings, the World Health Organization (WHO) has recommended a maximum permissible limit $\left(5 \mu \mathrm{g} \mathrm{L}^{-1}\right)$ for cadmium in normal blood. ${ }^{3}$ In addition, along with increased industrialization, cadmium pollution has become increasingly serious. Consequently, the development of high-efficiency methods for the removal of cadmium from wastewater samples is a pressing task. ${ }^{4}$

At present, reliable treatment technologies have been developed for wastewater containing cadmium, including chemical precipitation, the ferrite method, ion exchange method, electrocoagulation, membrane separation, and adsorption. ${ }^{5}$ Chemical precipitation is a low-cost treatment but not environmentally sound. ${ }^{6}$ Stephanie et al. ${ }^{7}$ added sodium decanoate as a precipitant to selective precipitation of cadmium, but a mass of waste residue was left behind. Khaled ${ }^{8}$ designed a new electrocoagulation reactor for the removal of cadmium from phosphate industrial wastewater from phosphate production; however, the large energy consumption and high operational cost limit its widespread application. Comparatively, membrane filtration and ion-exchange resin are efficient processing methods for both inorganics and organics in wastewater. Wong et al. ${ }^{9}$ recommended that cadmium ions be removed by ion-exchange resin until its maximum sorption capacity has reached $2.2 \mathrm{mmol} / \mathrm{g}$. Mehdi et al. ${ }^{10}$ reported porous anionic exchange membranes for the removal of cadmium from wastewater; and Kamal et al. ${ }^{11}$ separated cadmium from wastewater by a liquid membrane-based

Received: June 15, 2015

Accepted: October 20, 2015

Published: November 2, 2015 


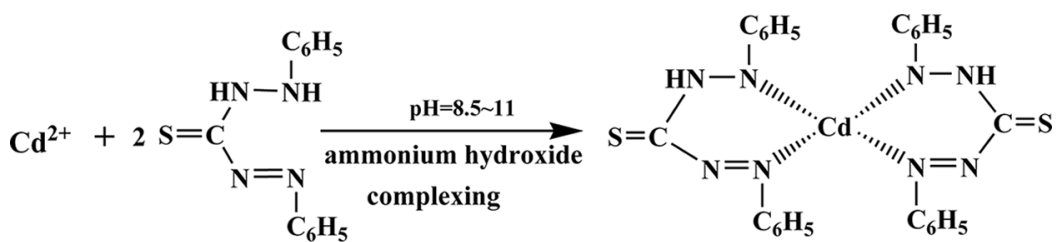

Cd(II)-dithizone complex

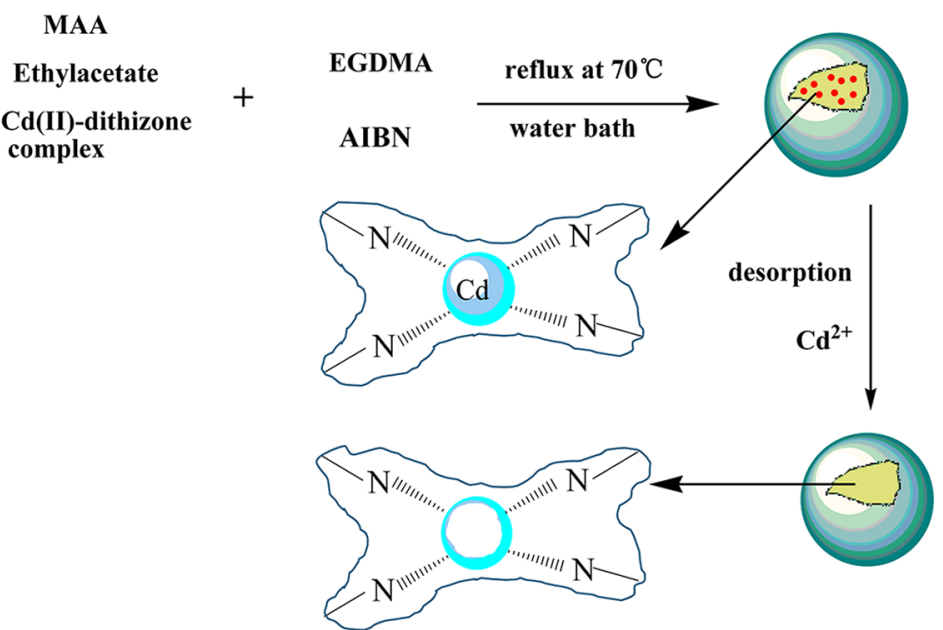

Figure 1. Synthesis route of Cd-IIP.

method, resulting in about a $79 \%$ recovery of cadmium. Nevertheless, this method has no special selectivity and poor performance in reuse. In addition, the membrane is easily fouled. Biosorption has become a popular technology for removing metal from wastewater because of its excellent adsorption performance but lacks a detailed mechanism for the adsorption sites. Eichhornia crassipes, Pinus halepensis sawdust, and Triticum aestivum were used for the adsorption of cadmium ion with a removal rate as high as $73.75 \%$; meanwhile, Abdulazi used activated carbon produced from rubber tires to evaluate the adsorption of cadmium. ${ }^{12-15}$ All of these methods failed to provide a detailed mechanism of adsorption and required a single adsorption environment. As a consequence, a novel material for complex matrices that satisfies the requirements of an environmentally friendly and economically efficient separation technique is essential and needs much more attention. Moreover, a detailed adsorption mechanism can contribute to the future industrial application of such a method.

One of the most widely used and effective pretreatment techniques for metal separation is adsorption by ion-imprinted polymers that have a strong preference for a specific target and produce no secondary pollution; this technique is rapid and effective, safe, and easy to regenerate. ${ }^{16}$ Guo et al. ${ }^{17}$ functionalized $-\mathrm{SH}$ onto a magnetic ion-imprinted polymer by surface imprinting for selective removal of $\mathrm{Pb}$ (II) from aqueous samples, and Luo et al. ${ }^{18}$ used a crown ether as a functional monomer by inverse emulsion polymerization for the selective removal of $\mathrm{Pb}(\mathrm{II})$, both of which methods have shown excellent selectivity and adsorption performance. Many researchers have made great progress in the preparation of cadmium imprinted polymers. Chen et al. ${ }^{19}$ through modification of thiourea onto magnetic ion-imprinted chitosan $/ \mathrm{TiO}_{2}$ reported a much higher adsorption capacity, $180 \mathrm{mg} / \mathrm{g}$, but the method required $120 \mathrm{~min}$ to reach saturation adsorption; Lü et al. ${ }^{20}$ imprinting a carboxymethyl chitosansilica hybrid reported $20.7 \mathrm{mg} / \mathrm{g}$ adsorption capacity in $30 \mathrm{~min}$; $\mathrm{Li}$ et $\mathrm{al}^{21}$ applied a polysaccharide-incorporated sol-gel to prepare a silica-supported organic-inorganic hybrid sorbent, for which the adsorption capacity reach $33.4 \mathrm{mg} / \mathrm{g}$; Guo et al. ${ }^{22}$ reported the adsorption of cadmium(II) ion in silica gel imprinted sorbents with an adsorption capacity of $30.8 \mathrm{mg} / \mathrm{g}$ which reached saturation adsorption in $30 \mathrm{~min}$; Candan et al. ${ }^{23}$ using ion-imprinted beads reported cadmium adsorption of $5.48 \mathrm{mg} / \mathrm{g}$. In this study, we got an adsorption capacity of 44.6 $\mathrm{mg} / \mathrm{g}$ in $20 \mathrm{~min}$. Dithizone was used to chelate nickel ion to form a complex to be used as a template molecule. Together with functional monomers, methylacrylic acid (MAA) was applied to an ion-imprinted polymer to prepare nickel ion selective membranes through bulk polymerization, and timepermeation curves of ions through the $\mathrm{Ni}$ (II) imprinted membrane required $48 \mathrm{~h}^{24,25}$ Herein, dithizone was applied to $\mathrm{Cd}(\mathrm{II})$ complexes, and the complex thus obtained was used as a template molecule together with functional monomer methylacrylic acid (MAA) resulting in homogeneous binding sites on the Cd-IIP by precipitation polymerization. However, there is still a big challenge to a prepare a novel cadmium ion imprinted polymer. We used solvent (ethyl acetate) to dissolve the coordination compound. The cross-linking agent ethylene glycol dimethacrylate (EGDMA) and 2,2-azobis(isobutyronitrile) (AIBN) as a initiator were added to obtain the Cd-IIP, and the adsorption equilibrium time is only approximately $20 \mathrm{~min}$. The adsorption environment was studied using batches of adsorption experiments to confirm the adsorption mechanism of Cd-IIP. These experiments 

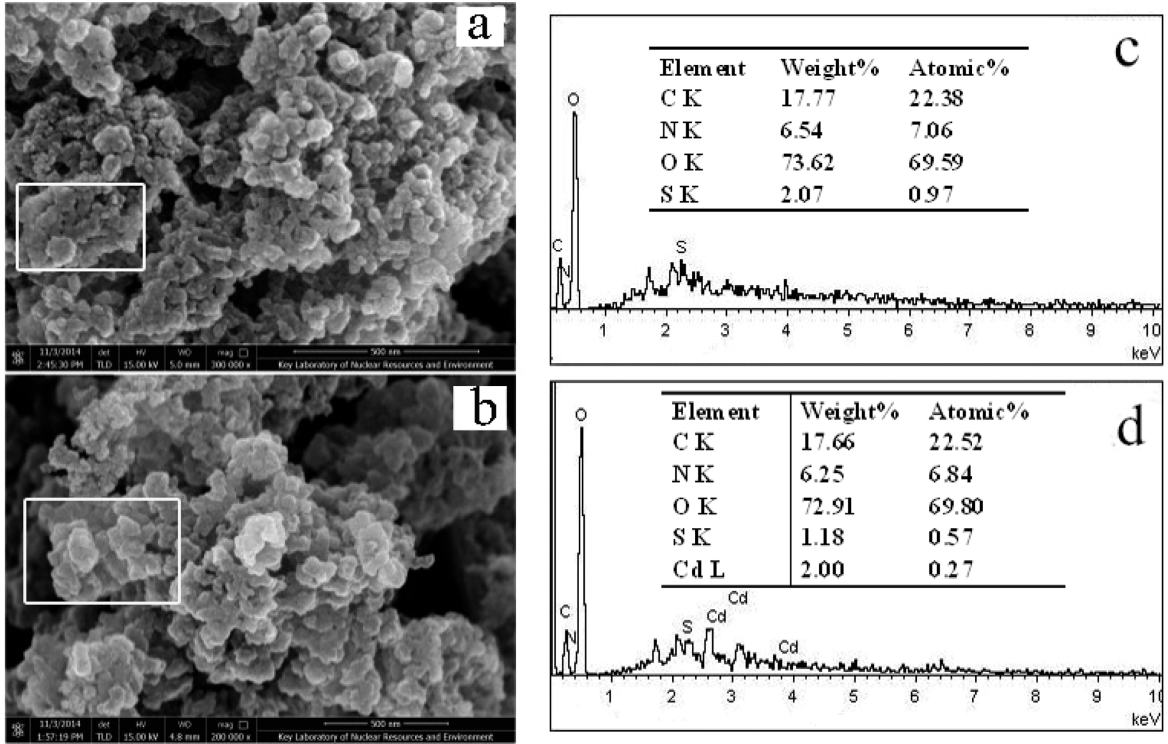

Figure 2. SEM photographs of Cd-IIP (a) and NIP (b) and EDX spectra of the free (a) and loaded (b) Cd(II) onto Cd-IIP.

include measured $\mathrm{pH}$, isotherms at different temperatures, kinetics at different initial concentrations, thermodynamics, adsorption energy, selectivity, recycling, and the mechanism of this adsorbent toward $\mathrm{Cd}(\mathrm{II})$.

\section{EXPERIMENTAL SECTION}

2.1. Reagents and Apparatus. Details for chemical reagents and instruments for characterization are described in the Supporting Information, text S1.

2.2. Synthesis of Cadmium Ion-Imprinted Polymer. The Cd-IIP was prepared by a precipitation polymerization technique that is shown in Figure 1.

The Cd-dithizone complex was primarily synthesized to serve as a template molecule; afterward, Cd-IIP and NIP were synthesized by the precipitation polymerization method (Supporting Information, text S2).

2.3. Batch Adsorption Experiments. Batch sorption experiments were carried out to test the adsorption property and mechanism of the cadmium ion imprinted.

The effect of $\mathrm{pH}$ on the cadmium adsorption process was studied over the $\mathrm{pH}$ range 1.0-7.0 ( $\mathrm{pH} 510$, Kesheng, Shenzhen); and the initial cadmium concentration was fixed at $200 \mathrm{mg} / \mathrm{L}$. The aqueous solutions of cadmium were adjusted to the desired $\mathrm{pH}$ levels using $0.1 \mathrm{M} \mathrm{HCl}$ or $0.1 \mathrm{M} \mathrm{NaOH}$. Next, $25 \mathrm{mg}$ of Cd-IIP were added to a conical flask that contained $50 \mathrm{~mL}$ of the above-mentioned solution and the conical flasks were shaken on an incubator shaker (Jingqi, ISRDD3, USA) at $25{ }^{\circ} \mathrm{C}$ and $120 \mathrm{rpm}$. After $4 \mathrm{~h}$, the samples were taken from the flasks. Finally, the cadmium concentrations $\left(C_{\mathrm{e}}\right)$ were measured by atomic absorption spectrometry (AAS). The Cd(II) uptake at equilibrium was calculated from eq 1 :

$$
Q=\frac{\left(C_{0}-C_{e}\right) V}{m}
$$

where $Q$ represents the adsorption capacity $(\mathrm{mg} / \mathrm{g}) ; C_{0}$ and $C_{\mathrm{e}}$ are the initial and equilibrium concentrations of cadmium ions $(\mathrm{mg} / \mathrm{L})$, respectively; $m$ is the mass of polymers $(\mathrm{g})$; and $V$ is the volume of the metal ion solution (L).
Batch adsorption experiments of isothermal adsorption, kinetics adsorption, and regeneration studies have detailed description in the Supporting Information, text S3.

Competitive sorption of $\mathrm{Zn}$ (II), $\mathrm{Cu}$ (II), $\mathrm{Co}$ (II), $\mathrm{Pb}$ (II) in the presence of $\mathrm{Cd}$ (II) was investigated for both cadmium ionimprinted or nonimprinted polymer. The initial concentrations of $\mathrm{Cd}(\mathrm{II}) / \mathrm{Zn}(\mathrm{II}), \mathrm{Cd}(\mathrm{II}) / \mathrm{Cu}(\mathrm{II}), \mathrm{Cd}(\mathrm{II}) / \mathrm{Co}(\mathrm{II})$ and $\mathrm{Cd}(\mathrm{II}) /$ $\mathrm{Pb}$ (II) in the binary aqueous solutions $(\mathrm{pH}=6.0 \pm 0.1)$ were $200 \mathrm{mg} / \mathrm{L}$. The distribution ratio $\left(K_{\mathrm{D}}, \mathrm{mL} / \mathrm{g}\right)$, the selectivity factor of $\mathrm{Cd}(\mathrm{II})$ with respect to other ions $\left(\alpha_{\mathrm{Cd} / \mathrm{M}}\right)$, and the relative selectivity factor $(\beta)$ were calculated using the following equations:

$$
\begin{aligned}
& K_{\mathrm{D}}=\frac{q_{\mathrm{e}}}{C_{\mathrm{e}}} \\
& \alpha=\frac{K_{\mathrm{D} 1}}{K_{\mathrm{D} 2}} \\
& \beta=\frac{\alpha_{1}}{\alpha_{2}}
\end{aligned}
$$

where $q_{\mathrm{e}}$ represents the adsorption capacity and $C_{\mathrm{e}}$ is the equilibrium concentration of $\mathrm{Cd}(\mathrm{II}) ; K_{\mathrm{D} 1}$ and $K_{\mathrm{D} 2}$ represent the distribution coefficient of $\mathrm{Cd}(\mathrm{II})$ and $\mathrm{D}_{2}\left(\mathrm{D}_{2}=\mathrm{Zn}(\mathrm{II}), \mathrm{Pb}(\mathrm{II})\right.$, $\mathrm{Co}(\mathrm{II})$, or $\mathrm{Cu}(\mathrm{II})) ; \alpha$ is the selectivity coefficient; $\beta$ is the relative selectivity coefficient; and $\alpha_{1}$ and $\alpha_{2}$ are the selectivity coefficients of Cd(II)-IIP and NIP, respectively.

\section{RESULTS AND DISCUSSION}

3.1. Morphology Study. The scanning electron microscopy (SEM) images of the Cd-IIP and NIP are shown in Figure 2a,b. We can recognize that both of Cd-IIP and NIP particles were packing in disorder. There is no obvious difference between Cd-IIP and NIP for the little variation on the surface area of Cd-IIP and NIP, they are $107.04 \mathrm{~m}^{2} / \mathrm{g}$ and $110.99 \mathrm{~m}^{2} / \mathrm{g}$, respectively.

The energy dispersive X-ray (EDX) analysis spectrum was employed to evaluate the elements on the surface of the Cd-IIP. It is possible for the spectrum to change following metal uptake. Comparing the EDX spectra before (Figure 2c) and 
after (Figure 2d) adsorption onto the Cd-IIP, there is an obvious cadmium peak in the EDX spectrum after adsorption, which indicates that cadmium was adsorbed on the Cd-IIP. Moreover, the ratio of the atom numbers of $S$ to $C d$ is 2.1 conforming to the complexation mechanism of dithizone with cadmium ions with molar ratio of 2 . The actual value being little greater than theoretical value may be attributed to the maximum adsorption capacity not reached.

3.2. The Influence of $\mathrm{pH}$. It is well-known that the $\mathrm{pH}$ of a solution is the most important variables affecting the amount of adsorption of heavy metal ions. It not only has an impact on the protonation of the functional groups on the sorbents but also the solution chemistry properties of the heavy metal ions (such as hydrolysis, complexation, and redox reaction). ${ }^{26}$ Precipitation of cadmium hydroxide occurs, when the solution is estimated to be $\mathrm{pH}>8.2$ for $\mathrm{Cd}(\mathrm{OH})_{2}$ at the highest initial metal concentration of $5 \mathrm{mmol} / \mathrm{L}$ of $\mathrm{Cd}(\mathrm{II}){ }^{27}$ Consequently, the effect of $\mathrm{pH}$ on $\mathrm{Cd}(\mathrm{II})$ adsorption by Cd-IIP and NIP were studied at different $\mathrm{pH}$ values ranging from 1 to 7 , as shown in Figure 3. It was evident that the efficiency of the $\mathrm{Cd}(\mathrm{II})$

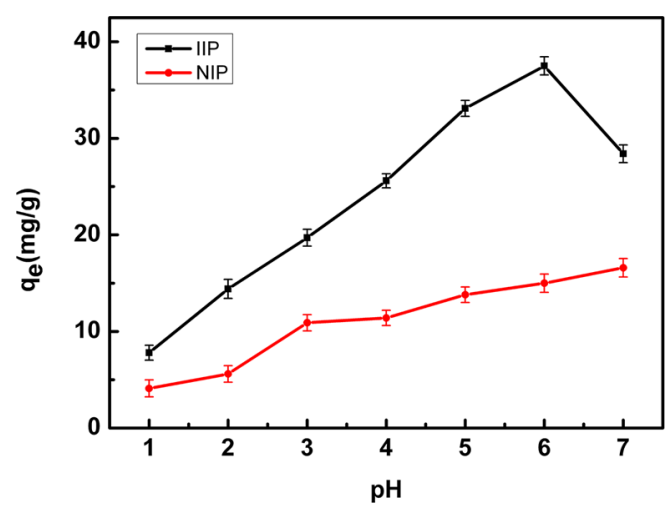

Figure 3. Effect of the $\mathrm{pH}$ of solution on equilibrium sorption capacity of $\mathrm{Cd}(\mathrm{II})$.

adsorption relied on the $\mathrm{pH}$ value of the aqueous solution. The amount of $\mathrm{Cd}$ (II) adsorbed onto the Cd-IIP was approximately 2.3 times that of the Cd-NIP, and the Cd(II) uptake performance was found to increase sharply with an increase in $\mathrm{pH}$ from 1 to 6 , and later decrease slightly at $\mathrm{pH}$ of 7 . When the $\mathrm{pH}$ is below $\mathrm{pH} 3.0$, the adsorption capacity of $\mathrm{Cd}(\mathrm{II})$ is low due to the protonation for the $\mathrm{Cd}(\mathrm{II})$-dithizone complex; when the $\mathrm{pH}$ is higher than $\mathrm{pH} 3.0$, a high adsorption capacity of $\mathrm{Cd}(\mathrm{II})$ is obtained as a result of deprotonation of the $\mathrm{Cd}(\mathrm{II})$-dithizone complex. It can be deduced from these results that the solution $\mathrm{pH}$ should be adjusted at $\mathrm{pH} 6$ to obtain the optimal adsorption efficiency, and the material can readily adsorb $\mathrm{Cd}$ (II) from solution in a range of $\mathrm{pH} 3-7$.

3.3. Adsorption Isotherm. Figure 4 and Figure S1 show the adsorption isotherms of Cd-IIP and NIP toward Cd(II) ions at $298 \mathrm{~K}, 308 \mathrm{~K}$ and $318 \mathrm{~K}$, respectively, and the detailed data of equilibrium concentration, adsorption capacity, and standard deviation for each temperature are shown in Table S1. It could be observed that the equilibrium adsorption capacity $\left(q_{\mathrm{e}}\right)$ of Cd-IIP and NIP for Cd(II) steadily increased as the initial concentration of Cd(II) increased from 40 to $200 \mathrm{mg} / \mathrm{L}$, and finally reached the maximum equilibrium adsorption capacity at $250 \mathrm{mg} / \mathrm{L}$ and $300 \mathrm{mg} / \mathrm{L}$, while the amount of Cd(II) adsorbed onto Cd-IIP was approximately 2.3 times of the Cd-NIP at different temperatures. At a constant ion

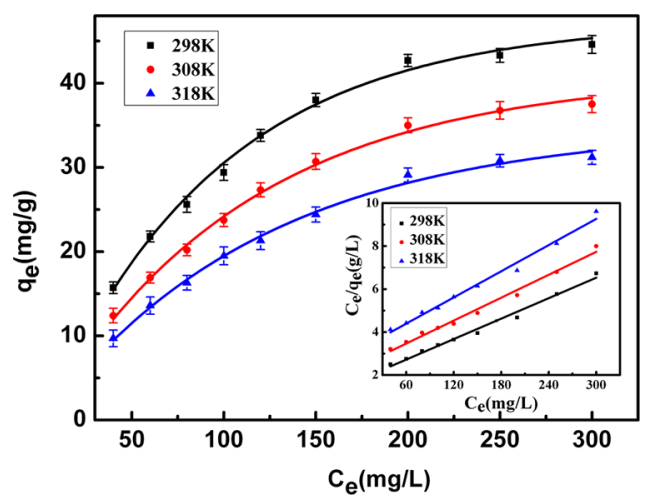

Figure 4. Adsorption isotherms for Cd-IIP adsorption at different temperatures, insert is the fitting plots of Langmuir model for adsorption isotherm.

concentration, the $\mathrm{Cd}(\mathrm{II})$ uptake dose slightly decreased as the temperature increased. This finding indicated that the adsorption of $\mathrm{Cd}(\mathrm{II})$ was an exothermic process.

Adsorption isotherm experiments have contributed to an understanding of the adsorption property of the cadmium ionimprinted polymer. Langmuir, Freundlich, and DubininRadusckevich $(\mathrm{D}-\mathrm{R})$ isotherms were generally employed to analyze the sorption data in the study. These isotherm modes help the comprehensive understanding of the relationship between the adsorbate and that adsorbed on the sorbent while the two phases were reaching the equilibrium state. ${ }^{28}$

The Langmuir model is a theoretical equation for which it is supposed that the binding sites on the outer surface of adsorbent are homogeneous and the adsorbate is adsorbed at well-defined sites, leading to monolayer coverage of the adsorbate surface. These sites are also presumed to be energetically identical and distant from each other as well, so that the adsorbed molecules have reactions with those adsorbed on adjacent sites. ${ }^{29}$ The Langmuir equation could be expressed in the illustrated as

$$
\frac{C_{\mathrm{e}}}{q_{\mathrm{e}}}=\frac{1}{b q_{\mathrm{m}}}+\frac{C_{\mathrm{e}}}{q_{\mathrm{m}}}
$$

where $q_{\mathrm{e}}(\mathrm{mg} / \mathrm{g})$ and $C_{\mathrm{e}}(\mathrm{mg} / \mathrm{L})$ are the equilibrium metal ion adsorption amount and concentration in the solution, respectively. The quantity $q_{\mathrm{m}}(\mathrm{mg} / \mathrm{g})$ is the maximum adsorption capacity of metal ions on the ion-imprinted polymer, $b(\mathrm{~L} / \mathrm{mg})$ is a constant of the Langmuir model.

The essential feature of the Langmuir isotherm is $R_{\mathrm{L}}$, which is a dimensionless equilibrium parameter that can be predicted. It can be defined as

$$
R_{\mathrm{L}}=\frac{1}{1+b C_{0}}
$$

where $b$ is the Langmuir isotherm constant and $C_{0}(\mathrm{mg} / \mathrm{L})$ is the initial concentration of $\mathrm{Cd}(\mathrm{II})$. The value of $R_{\mathrm{L}}$ at different temperatures in the Cd-IIP and NIP studies was calculated and shown in Figure S2a,b. When the value of $R_{\mathrm{L}}$ is between 0 and 1 , this suggests favorable adsorption for all the initial concentrations and temperatures studied. Otherwise, a value of $R_{\mathrm{L}}>1$ indicated unfavorable adsorption.

The Freundlich equation is an empirical expression which is employed to describe a multilayer adsorption on the heterogeneous system. The Freundlich equation can be expressed as 
Table 1. Freundlich, Langmuir, and D-R Model Constants of Cd(II) Adsorption on the Cd-IIP at Different Temperatures

\begin{tabular}{|c|c|c|c|c|c|c|c|c|c|}
\hline \multirow{2}{*}{$\frac{T}{\mathrm{~K}}$} & \multicolumn{3}{|c|}{ Freundlich isotherm parameters } & \multicolumn{3}{|c|}{ Langmuir isotherm parameters } & \multicolumn{3}{|c|}{ Duninin-Radushkevich parameters } \\
\hline & $n$ & $K_{\mathrm{F}}$ & $R^{2}$ & $q_{\mathrm{m}}$ & $b$ & $R^{2}$ & $K_{\mathrm{DR}}$ & $E$ & $R^{2}$ \\
\hline 298 & 1.895 & 2.483 & 0.953 & 63.0 & 0.009 & 0.988 & 0.0206 & 4.92 & 0.977 \\
\hline 308 & 1.798 & 1.789 & 0.931 & 56.3 & 0.007 & 0.987 & 0.0212 & 4.85 & 0.971 \\
\hline 318 & 1.682 & 1.186 & 0.969 & 49.3 & 0.006 & 0.986 & 0.0215 & 4.81 & 0.969 \\
\hline
\end{tabular}

$$
\ln q_{\mathrm{e}}=\frac{1}{n} \ln C_{\mathrm{e}}+\ln K_{\mathrm{F}}
$$

where $K_{\mathrm{F}}\left((\mathrm{mg} / \mathrm{g})(\mathrm{L} / \mathrm{mg})^{1 / n}\right)$ and $1 / n$ are the Freundlich constants and relate to adsorption capacity and adsorption intensity. If the value of $1 / n$ is in the range of 0 to 1 , the adsorption process is feasible and favorable.

The fitting results and constant parameters of the adsorption were calculated from the Langmuir and Freundlich equations for Cd-IIP and NIP and are given in Table 1 and Table S2, respectively. The values of correlation coefficients $(>0.98)$ of the Langmuir model were a little higher than the values fitting the other two models in all three temperatures studies, indicating that the Langmuir mode was applicable to the adsorption data; the outer surface of the adsorbent is homogeneous and the adsorbate is adsorbed at well-defined sites which identify with the characteristics of the ion imprinting specificity. The values of $q_{\mathrm{m}}$ decreased with the increase in temperature, which was consistent with experimental data. The values of $R_{\mathrm{L}}$ and $1 / n$ are all in the range of 0 to 1 , confirming the favorable uptake of the adsorption process. Figure $\mathrm{S} 2$ shows the lower $R_{\mathrm{L}}$ values at higher initial concentrations of $\mathrm{Cd}$ (II) in solution, indicating that adsorption was more favorable at higher concentrations which was in accordance with the results obtained from the adsorption isotherms. In addition, adsorption on Cd-IIP was more favorable than on Cd-NIP at a constant concentration, suggesting that the Cd-IIP showed much more excellent adsorption performance than Cd-NIP.

The $\mathrm{D}-\mathrm{R}$ isotherm is similar to the implication of Langmuir isotherm, which assumes the adsorption of single type of uniform pores. In this study, Langmuir mode was applicable to the adsorption data, here, $\mathrm{D}-\mathrm{R}$ equation can be employed to distinguish physisorption of metal ions from their chemisorption. One of the best feature of the $\mathrm{D}-\mathrm{R}$ equation lies on the fact that it is temperature-dependent. Combined with the data adsorption isotherms of Cd-IIP and NIP toward Cd(II), the adsorption capacity clearly varies with temperatures. The $D-R$ isotherm model was applied to estimate the porosity apparent free energy, and the characteristics of adsorption ${ }^{30,31}$ which best fit the data are defined by the following equation:

$$
\begin{aligned}
& \ln q_{\mathrm{e}}=\ln q_{\mathrm{m}}-K_{\mathrm{DR}} \varepsilon^{2} \\
& \varepsilon^{2}=R T \ln \left(1+\left(1 / C_{\mathrm{e}}\right)\right) \\
& E=\left(2 K_{D R}\right)^{-1 / 2}
\end{aligned}
$$

where $q_{\mathrm{e}}(\mathrm{mg} / \mathrm{g})$ and $q_{\mathrm{m}}(\mathrm{mg} / \mathrm{g})$ are the equilibrium and theoretical maximum capacity, respectively; $K_{\mathrm{DR}}\left((\mathrm{mol} / \mathrm{J})^{2}\right)$ is the activity coefficient related to the free energy of adsorption; $\varepsilon$ is the Polanyi potential; $R$ is the ideal gas constant $(8.314 \mathrm{~J}$. $\left.\mathrm{mol}^{-1} \cdot \mathrm{K}^{-1}\right), T(\mathrm{~K})$ is the absolute temperature, $C_{\mathrm{e}}$ is the equilibrium concentration; and $E(\mathrm{~J} / \mathrm{mol})$ is the mean adsorption energy.
Adsorption energy is germane to the adsorption process: when $E$ is less than $8 \mathrm{~kJ} / \mathrm{mol}$, physisorption is the major process, otherwise chemisorption is the predominant adsorption procedure. ${ }^{32,33}$ The correlation coefficient values of $\mathrm{D}-\mathrm{R}$ model $(>0.96)$ are also high, suggesting that its fittings are reliable. Thus, for the adsorption energy $(E)$ of Cd-IIP and NIP, shown in Table 1 and Table S2, both data values are less than $8 \mathrm{~kJ} / \mathrm{mol}$, suggesting that physisorption is the dominant adsorption mechanism.

3.4. Adsorption Thermodynamics. The thermodynamic parameters including standard free energy change $\Delta G^{0}(\mathrm{~kJ}$. $\left.\mathrm{mol}^{-1}\right)$, enthalpy change $\Delta H^{0}\left(\mathrm{~kJ} \cdot \mathrm{mol}^{-1}\right)$ and entropy change $\Delta S^{0}\left(\mathrm{~J} \cdot \mathrm{K}^{-1} \cdot \mathrm{mol}^{-1}\right)$ can be calculated from the following equations:

$$
\begin{aligned}
& \Delta G^{0}=-R T \ln K \\
& \ln K=\frac{\Delta H^{0}}{R T}+\frac{\Delta S^{0}}{R} \\
& \Delta S^{0}=\frac{\Delta H^{0}-\Delta G^{0}}{T}
\end{aligned}
$$

where $R$ is the gas constant $\left(8.314 \mathrm{~J} \cdot \mathrm{mol}^{-1} \cdot \mathrm{K}^{-1}\right), T$ is the absolute temperature, and $K$ is the thermodynamic equilibrium constant in the adsorption process, which was determined using the method of $\mathrm{Wu}$ and $\mathrm{Yu}^{34}$ by plotting $\ln \left(q_{\mathrm{e}} / C_{\mathrm{e}}\right)$ versus $q_{\mathrm{e}}$ and extrapolating to zero $q_{\mathrm{e}}$. Meanwhile, $\Delta S^{0}$ and $\Delta H^{0}$ are the

\begin{tabular}{|c|c|c|c|}
\hline$T$ & $\Delta G^{0}$ & $\Delta H^{0}$ & $\Delta S^{0}$ \\
\hline $\mathrm{K}$ & $\mathrm{kJ} / \mathrm{mol}$ & $\mathrm{kJ} / \mathrm{mol}$ & $\mathrm{kJ} / \mathrm{mol} \mathrm{K}$ \\
\hline 298 & -16.20 & -25.31 & -30.59 \\
\hline 308 & -15.86 & & \\
\hline 318 & -15.26 & & \\
\hline
\end{tabular}
intercept and slope, respectively, of the straight line which was plotted by $\ln K$ as a function of $10^{3} / T$.

The thermodynamic parameters of the sorption of $\mathrm{Cd}(\mathrm{II})$ onto the Cd-IIP and NIP were given in Table 2 and Table S3.

Table 2. Thermodynamic Parameters of Cd(II) Adsorption onto the Cd-IIP at Different Temperatures

The negative values of $\Delta G^{0}$ suggested that the adsorption process was spontaneous with a high preference of $\mathrm{Cd}$ (II) for the Cd-IIP and NIP. The higher negative value of $\Delta G^{0}$ reflects a more energetically favorable adsorption which was consistent with the adsorption isotherm results that showed that the optimal adsorption temperature is $298 \mathrm{~K}^{35}$ The negative values of the enthalpy change $\Delta H^{0}$ indicated that the adsorption processes were exothermic. Normally, enthalpy value changes between 40 and $120 \mathrm{~kJ} / \mathrm{mol}$ are attributed to chemisorption, otherwise the values indicate physisorption. ${ }^{36}$ Therefore, the values of $\Delta H^{0}$ (IIP: $-25.31 \mathrm{~kJ} / \mathrm{mol}$, NIP: $-17.18 \mathrm{~kJ} / \mathrm{mol}$ ) in this study suggested that the adsorption processes were regarded as physisorption, and the interactions between the polymeric materials and the cadmium ion are mainly 
electrostatic (Coulombic interactions) and van der Waals. The negative value of $\Delta S^{0}$ means a decrease in the freedom during the adsorption, which resulted in significant changes in the internal structure of the absorbent during the adsorption processes.

3.5. Adsorption Kinetics. The time to reach equilibrium is an important parameter for evaluating the efficiency of adsorption. It can be observed from Figure 5 and Figure 3S

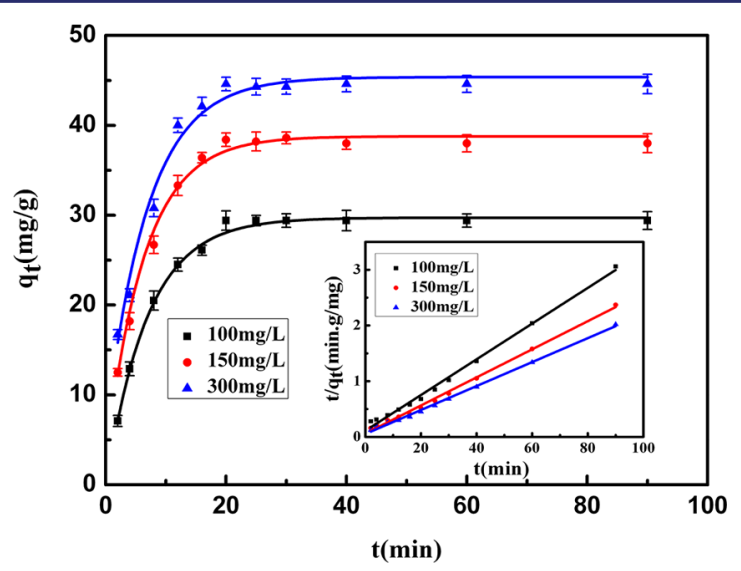

Figure 5. Kinetic adsorption cadmium on Cd-IIP at different initial $\mathrm{Cd}(\mathrm{II})$ concentrations. The inset is the fitting plots of the pseudosecond-order kinetic model for $\mathrm{Cd}(\mathrm{II})$ adsorption.

that the adsorption capacity of $\mathrm{Cd}(\mathrm{II})$ onto Cd-IIP and NIP increases rapidly during the initial $12 \mathrm{~min} ; 8 \mathrm{~min}$ later the adsorption capacity slowed, then leveled off as equilibria were arrived at the different initial concentrations of $\mathrm{Cd}(\mathrm{II})$. The equilibrium adsorption capacity was greater with higher initial concentrations of $\mathrm{Cd}(\mathrm{II})$. The high initial adsorption rate may be due to the strong complexation, plenty of adsorption sites, the high affinity of imprinted cavities of Cd-IIP for Cd(II), and the geometric matching between $\mathrm{Cd}(\mathrm{II})$ ions and the imprinted cavities.

To further study the mechanism of adsorption and to determine its potential rate-controlling steps that contain the chemical reaction processes and mass transport, kinetic models including pseudo-first-order, pseudo-second-order, and Weber's intraparticle diffusion model have been employed to analyze the experimental data. These data can be expressed as follows:

$$
\begin{aligned}
& \ln \left(q_{\mathrm{e}}-q_{t}\right)=\ln q_{\mathrm{e}}-k_{1} t \\
& \frac{t}{q_{t}}=\frac{1}{h_{0}}+\frac{t}{q_{e}} \quad \text { where, } h_{0}=k_{2} q_{\mathrm{e}}^{2} \\
& q_{t}=k_{i} t^{0.5}+c
\end{aligned}
$$

where $t$ is the contact time $(\mathrm{min}), q_{t}$ and $q_{\mathrm{e}}$ are the individual amounts of $\mathrm{Cd}(\mathrm{II})$ adsorbed at an arbitrary time $t$ and at equilibrium $(\mathrm{mg} / \mathrm{g}), k_{1}\left(\mathrm{~min}^{-1}\right)$ is the pseudo-first-order rate constant, $\mathrm{h}_{0}(\mathrm{mg} / \mathrm{g} \mathrm{min})$ is the initial adsorption rate, $k_{2}(\mathrm{~g} /$ $\left.(\mathrm{mg} \mathrm{min})^{-1}\right)$ is the pseudo-second-order rate constant, and $k_{\mathrm{i}}$ $\left(\mathrm{mg} / \mathrm{g} \mathrm{min}^{0.5}\right)$ is the rate constant for Weber's intraparticle diffusion model. The parameters of the adsorption were calculated from the Langmuir, Freundlich, and D-R equations for Cd-IIP and NIP.

The kinetic data with a good correlation clearly illuminates the mechanism of the adsorption of metal ions in the solid phase. The pseudo-second-order fitting plots of Cd-IIP and NIP are narrowed in Figure 5 and Figure 3S. The kinetic parameters of the adsorption were calculated from pseudo-firstorder, pseudo-second-order, and Weber's intraparticle diffusion model for Cd-IIP and NIP and are presented in Table 3 and Table S4, respectively. In contrast with the pseudo-first-order model, high correlation coefficients are obtained (IIP: $R^{2}>$ 0.995 , NIP: $\left.R^{2}>0.997\right)$. When the pseudo-second-order model is expanded to all concentrations, the calculated $q_{\mathrm{e}}$ is extremely close to the experimental data $\left(q_{\text {exp }}\right)$. The initial high rate $\left(h_{0}\right)$ of $\mathrm{Cd}(\mathrm{II})$ adsorption increases rapidly with an increase of $C_{0}$ of $\mathrm{Cd}(\mathrm{II})$.

Figure 6 and Figure S4 show the multilinear plots of Cd-IIP and NIP with Weber's intraparticle diffusion, which revealed

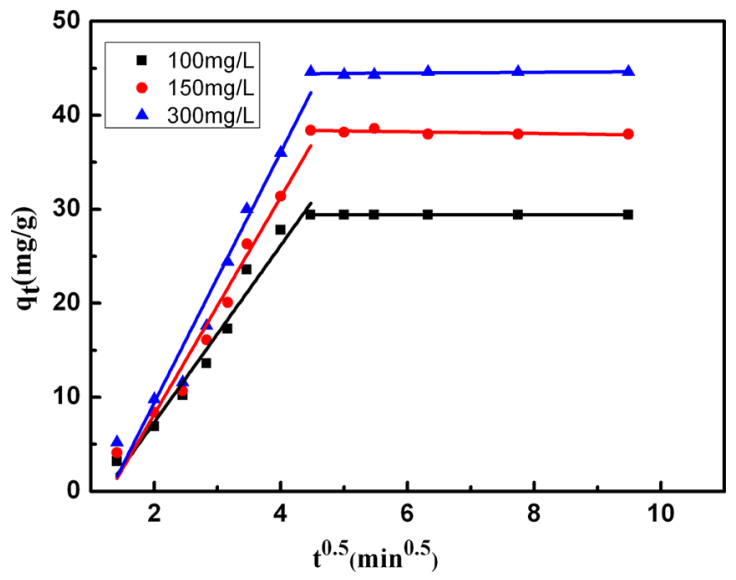

Figure 6. Fitting plots of intraparticle diffusion model for cadmium adsorption by Cd-IIP at different initial Cd(II) concentrations.

that there are two steps happening in the adsorption process. These two steps include film diffusion which is the diffusion of cadmium ions from solution to the external surface of the CdIIP and NIP (with particle adsorption at a site), and intraparticle diffusion, that is, ion diffusion into the interior of the adsorbent. The rate constants were listed in Table 3 and S4. It can easily be observed that $k_{\mathrm{i} 1}$ shows an increase in the rate constant for film diffusion with an increasing initial concentration of cadmium, and that the value of $k_{\mathrm{i} 2}$ was so small that the intraparticle diffusion in the adsorption process can be ignored. The plots in Figure 6 have no zero intercept, ${ }^{37}$

\begin{tabular}{|c|c|c|c|c|c|c|c|c|c|}
\hline \multirow[t]{2}{*}{$\mathrm{C}_{0}$} & \multicolumn{3}{|c|}{ pseudo-first-order } & \multicolumn{3}{|c|}{ pseudo-second-order } & \multicolumn{3}{|c|}{ intraparticle diffusion } \\
\hline & $k_{1}$ & $q_{\mathrm{e}}$ & $R^{2}$ & $k_{2} \cdot 10^{-3}$ & $q_{\mathrm{e}}$ & $h_{0}$ & $R^{2}$ & $k_{\mathrm{i} 1}$ & $k_{\mathrm{i} 2}$ \\
\hline 100 & 0.139 & 28.4 & 0.992 & 9.3 & 31.2 & 9.07 & 0.995 & 9.43 & 0 \\
\hline 150 & 0.196 & 43.6 & 0.971 & 11.0 & 39.6 & 16.84 & 0.996 & 11.57 & -0.091 \\
\hline 300 & 0.181 & 46.2 & 0.971 & 8.9 & 46.5 & 19.16 & 0.997 & 13.34 & 0.039 \\
\hline
\end{tabular}

Table 3. Kinetic Parameters of the Pseudo-first-order, Pseudo-second-order, and Weber's Intraparticle Diffusion Model for CdIIP 
suggesting that intraparticle diffusion was present, but it was not the rate-limiting step.

3.6. Selectivity of Cd(II)-IIP and NIP. $\mathrm{Zn}(\mathrm{II}), \mathrm{Co}(\mathrm{II})$, $\mathrm{Pb}(\mathrm{II})$, and $\mathrm{Cu}(\mathrm{II})$ are chosen as the competitor ions on account of their identical charge and similar size. Figure 7

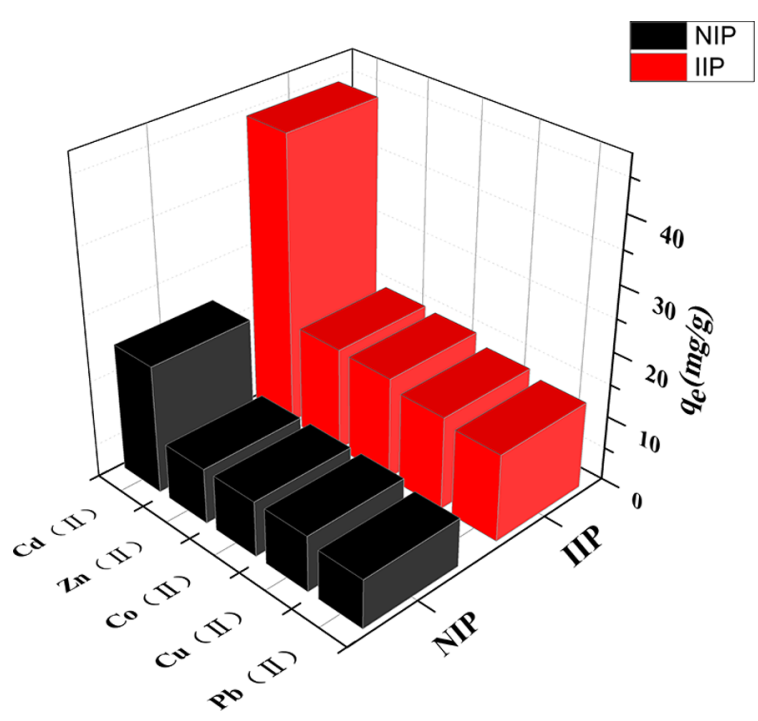

Figure 7. Selectivity of $\mathrm{Cd}(\mathrm{II})$ adsorption by Cd-IIP and NIP.

shows the uptake of $\mathrm{Pb}(\mathrm{II}), \mathrm{Zn}(\mathrm{II}), \mathrm{Co}(\mathrm{II}), \mathrm{Cu}(\mathrm{II})$, and $\mathrm{Cd}(\mathrm{II})$ by Cd-IIP and NIP. It can be observed that Cd-IIP and NIP exhibit a much larger adsorption capacity for $\mathrm{Cd}$ (II) than for other ions and selectivity for other metal ions except other than $\mathrm{Cd}(\mathrm{II})$ is absent.

The distribution ratios, selectivity factors, and relative selectivity coefficients were calculated in Table 4 . We can see

Table 4. Selective Adsorption Property of Cd-IIP and NIP

\begin{tabular}{|c|c|c|c|c|c|c|c|}
\hline \multirow[b]{2}{*}{ metal ions } & \multirow[b]{2}{*}{$\Phi(\mathrm{pm})$} & \multirow[b]{2}{*}{$\log \beta_{n}$} & \multicolumn{2}{|c|}{ Cd(II)-IIP } & \multirow[b]{2}{*}{$\beta$} & \multicolumn{2}{|c|}{ Cd(II)-NIP } \\
\hline & & & $K_{\mathrm{D}}$ & $\alpha$ & & $K_{\mathrm{D}}$ & $\alpha$ \\
\hline Cd(II) & 95 & 16.4 & 217.3 & & & 93.67 & \\
\hline $\mathrm{Zn}(\mathrm{II})$ & 74 & 16.4 & 71.3 & 3.05 & 1.32 & 40.6 & 2.31 \\
\hline $\mathrm{Pb}(\mathrm{II})$ & 119 & 18.3 & 79.1 & 2.75 & 1.64 & 55.9 & 1.68 \\
\hline $\mathrm{Cu}(\mathrm{II})$ & 73 & 18.7 & 79.4 & 2.74 & 1.23 & 42 & 2.23 \\
\hline $\mathrm{Co}(\mathrm{II})$ & 74.5 & 16.3 & 88.1 & 2.47 & 1.18 & 44.9 & 2.09 \\
\hline
\end{tabular}

that the distribution ratio of the Cd-IIP for $\mathrm{Cd}(\mathrm{II})$ was much greater than that of the Cd-NIP. Furthermore, the relative selectivity factors of the ion-imprinted polymer for each individual metal ion were greater than 1.68. Each individual metal with its ionic radius $(\Phi)$ and the stability constants of its complexes with EDTA $\left(\log \beta_{n}\right)$ is also listed in Table 4. The stability constants of dithizone are similar to those of EDTA because when the coordinating atoms are the same, there will be a similar ligand structure for the same metal. The above results implied that the imprinted cavities and specific binding sites in a predetermined orientation were formed in the Cd-IIP, and the sizes of $\mathrm{Pb}(\mathrm{II}), \mathrm{Zn}(\mathrm{II}), \mathrm{Co}(\mathrm{II})$, and $\mathrm{Cu}(\mathrm{II})$ do not match well with the cavity imprinted by $\mathrm{Cd}(\mathrm{II})$, although its stability constants higher than $\mathrm{Cd}(\mathrm{II})$, resulting in a high recognition ability and high selectivity of Cd-IIP for the Cd(II) ions.

3.7. Adsorption Mechanism. FTIR spectra (Figure 8a,b) were used to confirm the functional groups and surface properties of the Cd-IIP, which was analyzed in the range of 400 to $4000 \mathrm{~cm}^{-1}$ both in the free state and loaded with Cd(II). We can clearly see that change in band shifts and the intensities decrease for several bands. The peaks (curve a) at $1161 \mathrm{~cm}^{-1}$ and $1259 \mathrm{~cm}^{-1}$ were the stretching vibration of the $\mathrm{C}-\mathrm{N}$ bond in the $\mathrm{N}-\mathrm{C}=\mathrm{S}$ and $\mathrm{C}-\mathrm{N}-\mathrm{N}$ groups, the $1389 \mathrm{~cm}^{-1}$ peak was the $\mathrm{C}-\mathrm{N}=\mathrm{N}$ stretching vibration in dithizone. All three groups had shifted to 1163,1261 , and $1392 \mathrm{~cm}^{-1}$, respectively (curve b), which was evidenced that the $\mathrm{N}$ groups were related to $\mathrm{Cd}$ (II) adsorption. The reason for the wavenumber increase is that the $\mathrm{N}$ donated the electron to the metal ion $\mathrm{Cd}(\mathrm{II})$ then generated an electron transition. Bands at approximately 2987 $\mathrm{cm}^{-1}$ and $3451 \mathrm{~cm}^{-1}$ were observed because of the stretching vibration of the $\mathrm{N}-\mathrm{H}$ group in dithizone. The $3451 \mathrm{~cm}^{-1}$ peak that almost vanished is attributed to the $\mathrm{H}$ in the $\mathrm{N}-\mathrm{H}$ group that was replaced by the metal ion Cd(II). A conclusion can be drawn, that the amino group is the major functional group involved in cadmium bonding.

XPS was further performed to confirm the adsorption mechanism. The typical XPS wide scan spectra for Cd-IIP are shown in Figure 8 panels $\mathrm{c}$ and d. Herein, the $\mathrm{N}$ 1s spectrum of the Cd-IIP (Figure 8c) could be decomposed into four peaks with the $398.48 \mathrm{eV}$ peak representing $\mathrm{N}-\mathrm{N}$, the $399.39 \mathrm{eV}$ peak representing $\mathrm{N}=\mathrm{N}$, the $400.39 \mathrm{eV}$ carboxyl nitrogen peak as $\mathrm{N}-\mathrm{N}-\mathrm{C}_{6} \mathrm{H}_{5}$, and the $401.74 \mathrm{eV}$ carboxyl nitrogen peak as $\mathrm{N}=\mathrm{N}-\mathrm{C}_{6} \mathrm{H}_{5}$. After adsorption (Figure $8 \mathrm{~d}$ ), the binding energy values of $\mathrm{N}-\mathrm{N}, \mathrm{N}=\mathrm{N}, \mathrm{N}-\mathrm{N}-\mathrm{C}_{6} \mathrm{H}_{5}$, and $\mathrm{N}=\mathrm{N}-\mathrm{C}_{6} \mathrm{H}_{5}$ groups increased to $398.57,399.95,400.95$, and $401.9 \mathrm{eV}$, respectively, which indicates that the $\mathrm{N}$ groups are involved in $\mathrm{Cd}(\mathrm{II})$ adsorption. A lone pair of electrons from the $\mathrm{N}$ atoms is shared with $\mathrm{Cd}(\mathrm{II})$, thus the electron cloud density of the $\mathrm{N}$ atoms is decreased, especially the $\mathrm{N}$ atom of the $\mathrm{N}=\mathrm{N}, \mathrm{N}-\mathrm{N}-\mathrm{C}_{6} \mathrm{H}_{5}$, and $\mathrm{N}=\mathrm{N}-\mathrm{C}_{6} \mathrm{H}_{5}$ bonds, which obviously shift owing to their relatively stronger conjugation effect compared to that of the $\mathrm{N}-\mathrm{N}$. Hence, the adsorption of Cd(II) was followed by a charge transfer from these groups to $\mathrm{Cd}(\mathrm{II})$, which confirmed that the $\mathrm{N}-\mathrm{N}, \mathrm{N}=\mathrm{N}$ groups served as the sorption sites.

3.8. Reusability Study and Application of Cd-IIP. The stability and reusability of Cd-IIP are key factors for improving the process economics (Figure 9); meanwhile, the applicability to real environmental water samples of the Cd-IIP is also necessary. The regenerated Cd-IIP was reused for five cycles of adsorption-desorption. It can be observed that the adsorption capacity of Cd-IIP was stable within the first three cycles with little decrease in the adsorption capacity for $\mathrm{Cd}(\mathrm{II})$, but that the adsorption capacity of Cd-IIP was approximately $22 \%$ and 32 $\%$ loss in the fourth and fifth cycles, respectively. It can be concluded that Cd-IIP exhibits relatively good adsorption efficiency after regeneration, and could be used repeatedly.

To validate the applicability of the Cd-IIP for the removal of $\mathrm{Cd}(\mathrm{II})$ ions in real environmental water samples, lake water (Tianyi Lake, Nanchang) and river water (Ganjiang river, Nanchang) were selected and analyzed. ${ }^{33}$ The lake water and river water were spiked with $10 \mathrm{mg} / \mathrm{L}$ of $\mathrm{Cd}(\mathrm{II}), \mathrm{Pb}(\mathrm{II}), \mathrm{Zn}(\mathrm{II})$, $\mathrm{Co}(\mathrm{II})$, and $\mathrm{Cu}(\mathrm{II})$, respectively. The several water samples (50 $\mathrm{mL}$ ) were treated with $100 \mathrm{mg}$ of Cd-IIP and Cd-NIP at an initial $\mathrm{pH}$ of 6.5 for $4 \mathrm{~h}$. The Cd-IIP and NIP show almost $90 \%$ and $46 \%$ removal efficiency, respectively, which suggests that Cd-IIP has a strong anti-interference ability in real environmental water samples. 

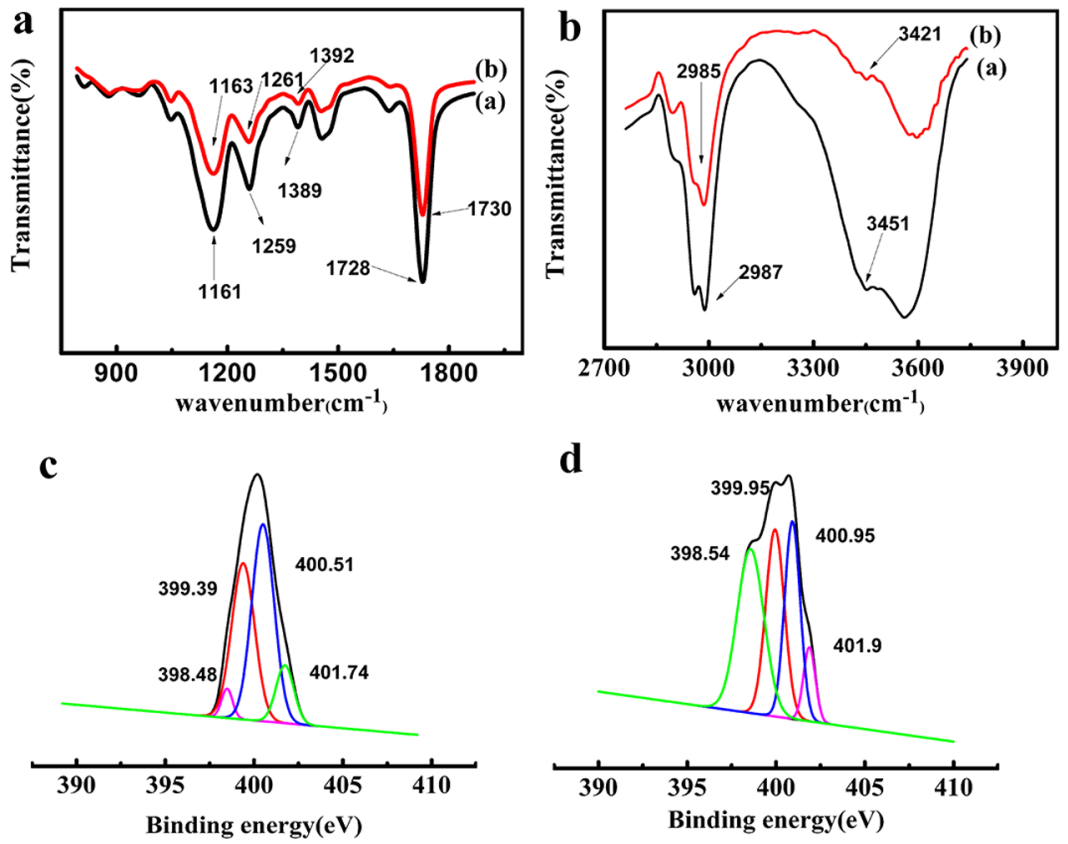

Figure 8. FT-IR spectra and N 1s of XPS spectra of the free (a) and loaded (b) Cd(II) onto Cd-IIP.

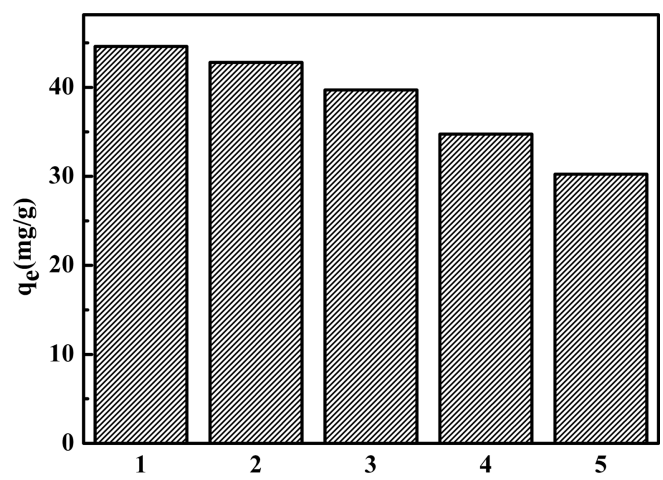

Figure 9. Reusability of Cd-IIP.

\section{CONCLUSIONS}

In the present work, a new Cd-IIP using MAA and dithizone as complexation agents was prepared for selective separation and decontamination of $\mathrm{Cd}$ (II) from aqueous and environmental samples. Both of these experiments demonstrated that several nitrogen functional groups were involved in the sorption of $\mathrm{Cd}(\mathrm{II})$ and that the $\mathrm{Cd}(\mathrm{II})$ adsorption on the ion-imprinted polymer was $\mathrm{pH}$ dependent. The adsorption isotherm data were better fitted to the Langmuir equation, indicating the formation of a monolayer coverage of $\mathrm{Cd}(\mathrm{II})$ on the ionimprinted polymer surface and the adsorbate is adsorbed at well-defined sites. The better fit of the pseudo-second-order kinetic model suggested that the rate-limiting step may be chemical adsorption. Thermodynamic parameters manifested that the adsorption was a spontaneous, exothermic process. The relative selectivity coefficients for $\mathrm{Cd}(\mathrm{II}) / \mathrm{Zn}(\mathrm{II}), \mathrm{Cd}(\mathrm{II}) /$ $\mathrm{Cu}(\mathrm{II}), \mathrm{Cd}(\mathrm{II}) / \mathrm{Co}$ (II) and $\mathrm{Cd}(\mathrm{II}) / \mathrm{Pb}(\mathrm{II})$ were greater than 1.68 , indicating that the imprinting technology resulted in the increased affinity of the imprinted polymer for $\mathrm{Cd}(\mathrm{II})$ over other metal ions compared with the nonimprinted polymer. Moreover, the imprinted polymer had a superior reusability and stability.

\section{ASSOCIATED CONTENT}

S Supporting Information

The Supporting Information is available free of charge on the ACS Publications website at DOI: 10.1021/acs.jced.5b00494.

Chemical reagents and apparatus; methods of synthesizing the complexes; batch adsorption experiments; additional figures and tables (PDF)

\section{AUTHOR INFORMATION}

\section{Corresponding Author}

*Tel.: +86 791 3953372. Fax: +86 791 395373. E-mail: luoxubiao@126.com.

\section{Funding}

This work was financially supported by Natural Science Foundation of China (51178213, 51238002, 51272099), and the National Science Fund for Excellent Young Scholars (51422807).

\section{Notes}

The authors declare no competing financial interest.

\section{REFERENCES}

(1) Gawin, M.; Konefal, J.; Trzewik, B.; Walas, S.; Tobiasz, A. Preparation of a new Cd (II)-imprinted polymer and its application to determination of cadmium (II) via flow-injection-flame atomic absorption spectrometry. Talanta 2010, 80, 1305-1310.

(2) Zhang, N.; Hu, B. Cadmium (II) imprinted 3-mercaptopropyltrimethoxysilane coated stir bar for selective extraction of trace cadmium from environmental water samples followed by inductively coupled plasma mass spectrometry detection. Anal. Chim. Acta 2012, 723, 54-60.

(3) Guidelines for Drinking-Water Quality Recommendations, 3rd ed.; World Health Organization: Geneva, 2006; Vol.1.

(4) Fang, G. Z.; Tan, J.; Yan, X. P. An ion-imprinted functionalized silica gel sorbent prepared by a surface imprinting technique combined with a sol-gel process for selective solid-phase extraction of cadmium (II). Anal. Chem. 2005, 77, 1734-1739. 
(5) Kumar, M.; Tripathi, B. P.; Shahi, V. K. Crosslinked chitosan/ polyvinyl alcohol blend beads for removal and recovery of Cd (II) from wastewater. J. Hazard. Mater. 2009, 172, 1041-1048.

(6) Ma, F.; Guo, J. B.; Zhao, L. J.; Chang, C. C.; Cui, D. Application of bioaugmentation to improve the activated sludge system into the contact oxidation system treating petrochemical wastewater. Bioresour. Technol. 2009, 100, 597-602.

(7) Mauchauffée, S.; Meux, E.; Schneider, M. Selective precipitation of cadmium from nickel cadmium sulphate solutions using sodium decanoate. Sep. Purif. Technol. 2008, 62, 394-400.

(8) Khaled, B.; Wided, B.; Béchir, H.; Limam, A.; Mouna, L.; Tlili, Z. Investigation of electrocoagulation reactor design parameters effect on the removal of cadmium from synthetic and phosphate industrial wastewater. Arabian J. Chem. 2014, DOI: 10.1016/ j.arabjc.2014.12.012.

(9) Wong, C. W.; Barford, J. P.; Chen, G.; McKay, G. Kinetics and equilibrium studies for the removal of cadmium ions by ion exchange resin. J. Environ. Chem. Eng. 2014, 2, 698-707.

(10) Garmsiri, M.; Mortaheb, H. R. Enhancing performance of hybrid liquid membrane process supported by porous anionic exchange membranes for removal of cadmium from wastewater. Chem. Eng. J. 2015, 264, 241-250.

(11) Bhatluri, K. K.; Manna, M. S.; Saha, P.; Ghoshal, A. K. Supported liquid membrane-based simultaneous separation of cadmium and lead from wastewater. J. Membr. Sci. 2014, 459, 256263.

(12) Módenes, A. N.; Espinoza-Quiñones, F. R.; Trigueros, D. E.; Lavarda, F. L.; Colombo, A.; Mora, N. D. Kinetic and equilibrium adsorption of $\mathrm{Cu}$ (II) and Cd (II) ions on Eichhornia crassipes in single and binary systems. Chem. Eng. J. 2011, 168, 44-51.

(13) Semerjian, L. Equilibrium and kinetics of cadmium adsorption from aqueous solutions using untreated Pinus halepensis sawdust. $J$. Hazard. Mater. 2010, 173, 236-242.

(14) Farooq, U.; Khan, M. A.; Athar, M.; Kozinski, J. A. Effect of modification of environmentally friendly biosorbent wheat (Triticum aestivum) on the biosorptive removal of cadmium (II) ions from aqueous solution. Chem. Eng. J. 2011, 171, 400-410.

(15) Al-Saadi, A. A.; Saleh, T. A.; Gupta, V. K. Spectroscopic and computational evaluation of cadmium adsorption using activated carbon produced from rubber tires. J. Mol. Liq. 2013, 188, 136-142.

(16) Zhai, Y.; Liu, Y.; Huang, X. Selective solid-phase extraction of trace cadmium (II) with an ionic imprinted polymer prepared from a dual-ligand monomer. Anal. Chim. Acta 2007, 593, 123-128.

(17) Guo, B.; Deng, F.; Au, C. Magnetic ion-imprinted and-SH functionalized polymer for selective removal of $\mathrm{Pb}$ (II) from aqueous samples. Appl. Surf. Sci. 2014, 292, 438-446.

(18) Luo, X. B.; Liu, L. L.; Luo, S. L. Novel ion-imprinted polymer using crown ether as a functional monomer for selective removal of $\mathrm{Pb}$ (II) ions in real environmental water samples. J. Mater. Chem. A 2013, $1,8280-8286$

(19) Chen, A.; Zeng, G.; Xie, G. Novel thiourea -modified magnetic ion-imprinted chitosan $/ \mathrm{TiO}_{2}$ composite for simultaneous removal of cadmium and 2,4 - dichlorophenol. Chem. Eng. J. 2012, 191, 85-94.

(20) Lü, H.; An, H.; Xie, Z. Ion-imprinted carboxymethyl chitosansilica hybrid sorbent for extraction of cadmium from water samples. Int. J. Biol. Macromol. 2013, 56, 89-93.

(21) Li, F.; Jiang, H.; Zhang, S. An ion-imprinted silica-supported organic-inorganic hybrid sorbent prepared by a surface imprinting technique combined with a polysaccharide incorporated sol-gel process for selective separation of cadmium (II) from aqueous solution. Talanta 2007, 71, 1487-1493.

(22) Guo, M. M.; Zhang, D. S.; Fan, X. L.; Y, F. Preparation, characterization and adsorption properties of cadmium(II) ion imprinted silica gel sorbents. J. Funct. Mater. 2013, 6, 800-804.

(23) Candan, N.; Tüzmen, N.; Andac, M.; Denizli, A. Cadmium removal out of human plasma using ion-imprinted beads in a magnetic column. Mater. Sci. Eng., C 2009, 29, 144-152.
(24) Vatanpour, V.; Madaeni, S. S.; Zinadini, S.; Rajabi, H. R. Development of ion imprinted technique for designing nickel ion selective membrane. J. Membr. Sci. 2011, 373, 36-42.

(25) Saraji, M.; Yousefi, H. Selective solid-phase extraction of Ni (II) by an ion-imprinted polymer from water samples. J. Hazard. Mater. 2009, 167, 1152-1157.

(26) Liu, Y.; Wang, W.; Wang, A. Adsorption of lead ions from aqueous solution by using carboxymethyl cellulose-g-poly (acrylic acid)/attapulgite hydrogel composites. Desalination 2010, 259, 258264.

(27) Lee, S. M.; Davis, A. P. Water Res. 2001, 35, 534-540.

(28) Chatterjee, S.; Woo, S. H. The removal of nitrate from aqueous solutions by chitosan hydrogel beads. J. Hazard. Mater. 2009, 164, 1012-1018.

(29) Kumar, M.; Tripathi, B. P.; Shahi, V. K. Crosslinked chitosan/ polyvinyl alcohol blend beads for removal and recovery of Cd (II) from wastewater. J. Hazard. Mater. 2009, 172, 1041-1048.

(30) Lu, X.; Shao, Y. S.; Gao, N. Y.; Ding, L. Equilibrium, Thermodynamic, and Kinetic Studies of the Adsorption of 2,4Dichlorophenoxyacetic Acid from Aqueous Solution by MIEX Resin. J. Chem. Eng. Data 2015, 60, 1259-1269.

(31) Ghaedi, M.; Hassanzadeh, A.; Kokhdan, S. N. Multiwalled Carbon Nanotubes as Adsorbents for the Kinetic and Equilibrium Study of the Removal of Alizarin Red S and Morin. J. Chem. Eng. Data 2011, 56, 2511-2520.

(32) Esmaeili, A.; Beni, A. A. A novel fixed-bed reactor design incorporating an electrospun PVA/chitosan nanofiber membrane. $J$. Hazard. Mater. 2014, 280, 788-796.

(33) Han, C.; Li, H.; Deng, L.; Luo, Y. Synthesis and characterization of mesoporous alumina and their performances for removing arsenic (V). Chem. Eng. J. 2013, 217, 1-9.

(34) Wu, J.; Yu, H. Q. Biosorption of 2, 4-dichlorophenol from aqueous solution by Phanerochaete chrysosporium biomass: Isotherms, kinetics and thermodynamics. J. Hazard. Mater. 2006, 137, 498-508.

(35) Chatterjee, S.; Woo, S. H. The removal of nitrate from aqueous solutions by chitosan hydrogel beads. J. Hazard. Mater. 2009, 164, 1012-1018.

(36) Alkan, M.; Demirbaş, Ö.; Celikcapa, S.; Doğan, M. Sorption of acid red 57 from aqueous solution onto sepiolite. J. Hazard. Mater. 2004, 116, 135-145.

(37) Chen, Z.; Zhang, J.; Fu, J.; Wang, M.; Xu, Q. Adsorption of methylene blue onto poly (cyclotriphosphazene-co-4, $4^{\prime}$-sulfonyldiphenol) nanotubes: Kinetics, isotherm and thermodynamics analysis. $J$. Hazard. Mater. 2014, 273, 263-271. 